\title{
Decision-making style profiles of pre-service biology teachers in socio-scientific issues
}

\author{
Marlina Ummas Genisa ${ }^{1}$, Bambang Subali ${ }^{2}$, Djukri $^{3}$, Habibi Habibi ${ }^{4}$ \\ ${ }^{1}$ Biology Education Department, Muhammadiyah University of Palembang, Indonesia \\ ${ }^{1}$ Educational Graduate School, Yogyakarta State University, Indonesia \\ ${ }^{2,3}$ Natural Science Departments, Yogyakarta State University, Indonesia \\ ${ }^{4}$ Physics Education, Universitas Pendidikan Mandalika, Indonesia
}

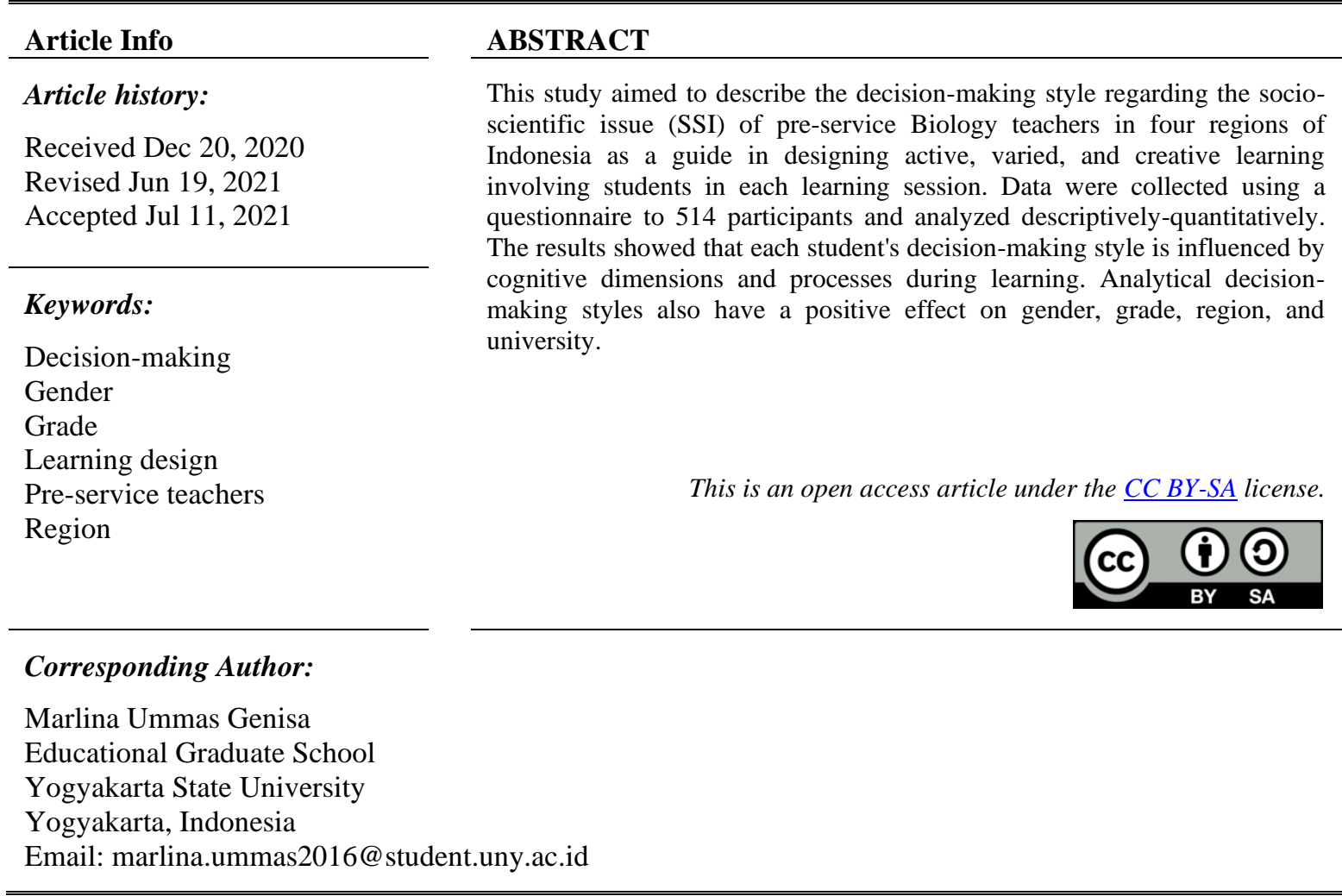

\section{INTRODUCTION}

In previous studies, it was found that decision-making is a determining factor for applying socioscientific issues in science learning [1]. Generally, decision making occurs every time in the thought process, however consciously or not, decision-making is part of a person's basic mental process and it is not a simple and easy as described. In the process, students need to have better knowledge about choices and able to assess their own knowledge about the choices [2], [3] to avoid unscientific decisions [4]. Demiral and Türkmenoğlu [5] states that there are three constituents in decision making, namely: decision-making situations, decision makers, and decision-making processes. The cognitive processes involved during the decision-making process can vary and depend on their environment and decision-making style. Decision making is closely related to cognitive processes because every decision making involves these processes. Lieder, et al. [6] explain that decision making is one of the fundamental human cognitive processes that are widely used in making rational, heuristic, and intuitive choices in complex scientific, engineering, economic, and management situations, as well as in almost every procedure in everyday life. The cognitive capacity of decision makers may vary widely, but the core cognitive processes of the human brain have similar characteristics and recursive mechanisms. This means that decision making will always involve cognitive processes in the human brain [7]-[9]. 
Decision theory can be categorized into two paradigms: descriptive and normative theory. Descriptive decision-making is based on empirical observations, whereas normative assumes rational decision makers who follow well-defined preferences who adhere to certain axioms of rational behavior. Rational and complex decision-making strategies can be classified into static and dynamic categories. Most of the existing decision-making strategies are static because the changing environment of the decision maker does not depend on the activities of the decision maker. In addition, different decision strategies can be chosen in the same situation or environment based on the decision makers' values and attitudes towards risk and their predictions on future outcomes. Based on this description, individual decision making can have different qualities because of its own contrasting processes. The study of individual differences that leads to the tendency to use one decision-making style over another can affect the performance of some of the complex tasks that have been performed [10].

A person's decision-making style can determine how decisions are made. Some experts explain that there are several styles of decision making: The analytical decision-making style according to Cosku [11] tends to a decision-making process that considers various components. This tendency explains that the analytical processing system consists of consciously controlled thinking, full of effort, and various competencies that are traditionally considered important for cognitive development and normative decision making. In the process, analytical processing is directed at breaking the problem into its component elements, examining the elements, therefore from this analysis is obtained: solutions, judgments, decisions and arguments. Calabretta, Gemser, and Wijnberg [12] also described that people can use various strategies when making decisions in complex tasks. In addition, the use of this decision strategy often depends on the nature of the decision situation itself. This suggests that people tend to process information more intuitively and analytically.

Students must be able to make the right decisions and then reflect on them as important factors in decision making. Sakschewskiet, et al. [13] explained that the self-reflection is important part to show students ability in decision-making. The accuracy of decision making requires self-reflection consideration in order to avoid students' doubts in making decisions, therefore students have high self-confidence in holding their decisions [14], [15]. The factors of gender, experience level, coverage area, depth of knowledge are very important things to consider in decision making. It is known that equal distribution of education causes imbalances in decision making, especially in science education. In addition, the influence of interactions between genders in a country and culture is also known to greatly influence a person in making the right decision.

Previous researches proved that these elements crucial especially in decision-making [16]-[24]. Therefore, this study intends to analyze of decision-making style based on self-reflection on making decision and provide data related to the effect of gender, grade, region, and universities. In the future, this study will serve as a guide in designing active, varied, creative, and student-centered learning models.

\section{RESEARCH METHOD}

This study employed descriptive-quantitative methods to explain data obtained through an online questionnaire survey. The sample was selected using purposive sampling technique. The samples were determined by subjects based on previously known population characteristics. The number of samples were 514 students from four regions in Indonesia, namely Makassar, Manokwari, Cirebon, and Palembang who were Biology students Education in semesters II, III, IV, VI and VIII. Data categories processing refers to the Average (M) and Standard Deviation (D) scores which are divided into 5 scales as shown in Table 1. A questionnaire containing 14 statements modified from Nygren [25] was distributed to various social media groups for pre-service biology teachers as in Table 2.

Table 1. Decision-making ability categories

\begin{tabular}{cc}
\hline Scores & Categories \\
\hline $\mathrm{X} \geq \mathrm{M}+1.5 \mathrm{SD}$ & Very high \\
$\mathrm{A}+0.5 \mathrm{D} \leq \mathrm{X} \leq \mathrm{A}+1.5 \mathrm{D}$ & High \\
$\mathrm{A}-0.5 \mathrm{D} \leq \mathrm{X} \leq \mathrm{A}+0.5 \mathrm{D}$ & Medium \\
$\mathrm{A}-1.5 \mathrm{D} \leq \mathrm{X} \leq \mathrm{A}-0.5 \mathrm{D}$ & Low \\
$\mathrm{X} \leq \mathrm{A}-1.5 \mathrm{D}$ & Very low \\
\hline
\end{tabular}


Table 2. Decision-making questionnaire

\begin{tabular}{|c|c|c|c|c|c|c|}
\hline \multirow{2}{*}{ No } & \multirow{2}{*}{ Statements } & \multicolumn{5}{|c|}{ Scales } \\
\hline & & 1 & 2 & 3 & 4 & 5 \\
\hline \multicolumn{7}{|c|}{ In making decisions about socio-scientific issues: } \\
\hline 1 & I have to identify the important factors that can influence it & & & & & \\
\hline 2 & I have to choose the most efficient solution to the problem & & & & & \\
\hline 3 & I first made the factors that had an important influence on my decision & & & & & \\
\hline 4 & I am very rational when evaluating risky options & & & & & \\
\hline 5 & I made a careful estimate of the situation first & & & & & \\
\hline 6 & I always pay attention to past information in making new decisions & & & & & \\
\hline 7 & I evaluate the weight of each piece of information & & & & & \\
\hline 8 & I always prepare myself as best I can before making decision & & & & & \\
\hline 9 & I try to observe the good and bad sides of each alternative & & & & & \\
\hline 10 & I like a rational and systematic approach to making decisions & & & & & \\
\hline 11 & I make careful consideration of all relevant information & & & & & \\
\hline 12 & I usually rely on careful reasoning in making decisions & & & & & \\
\hline 13 & I make it structured & & & & & \\
\hline 14 & I have to evaluate it systematically & & & & & \\
\hline
\end{tabular}

\section{RESULTS AND DISCUSSION}

\subsection{Decision-making style}

The main objective of this research is to describe statistically the decision-making style of preservice biology teachers in Indonesia based on gender, grade, region, and universities. Although various decision-making style assessments have been developed, the current study used a scale designed as shown in Table 2. He developed a measure to distinguish between people's tendencies to think more analytically or intuitively. The data obtained were analyzed to generally identify decision-making styles regarding socioscientific issues (SSI) of pre-service biology teacher and based on four characteristics, namely: gender, grade, region, and universities. The results of the overall analysis are shown in Figure 1.

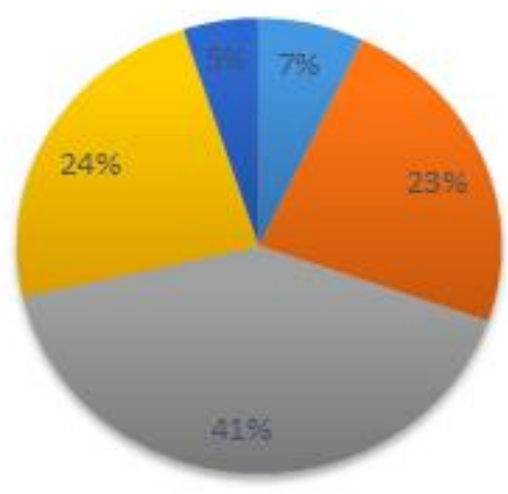

Figure 1. Decision-making style

Figure 1 shows that the categories of decision-making styles of 514 students were grouped into 5 categories, namely VH with the Very High category, $\mathrm{H}$ being the High category, while $\mathrm{M}$ for the Medium category, L indicating the Low category, and VL being the Very Low category. It can be seen that the students' analytic style is generally still in the Medium category (41\%). Percentages of decision styles from medium to very low have low analytical decision-making styles. Therefore, based on the data obtained, 70\% of students are classified as having a low analytical decision-making style and $30 \%$ having a high and very high decision-making style.

The results showed that the profile of decision-making styles of 514 in four regions in Indonesia indicated that the analytical decision-making style in general was categorized as low (70\%) and others were high and very high $(30 \%)$. Thus, pre-service biology teachers generally use a low-level analytical decisionmaking style to solve their problems. The influence of gender, grade, region and universities was found to be significant on decision-making styles, meaning that these factors can be considered in designing learning to encourage decision making. 


\subsection{Decision-making style based on gender, grade, region, and universities}

Decision making style based on gender, grade, region, and universities suggest that students in two extremely different locations and of different genders have different level of decision making. Based on these data, male's decision-making abilities are higher than female's. However, in general, both still have low decision-making style abilities. Students who come from western regions have higher decision-making style ability. However, in general still dominated by the medium to very low category. These results suggest that in terms of making the best decisions, both male and female always go through careful consideration by reviewing relevant information, but they are still inaccurate in reasoning and making decisions. Students from the east region use inappropriate reasoning than students from the west region and both still make unstructured decisions. In the process of making decisions, individuals tend to go through five stages, namely: problems understanding, seeking information, evaluating alternatives, making-decisions, and evaluating results. Related to the five stages above, referring to the theory of Nygren and White [26], an analytic decision-making style in which individuals will first seek as much information as possible, evaluate and weigh each alternative in detail, then make decisions about the options that are considered optimal. This study related to the low decision-making style of students is due to the fact that students are not accustomed to being faced with decision-making problems that require analytical skills, weigh, analyze and evaluate their decisions. In general, students are used to making general decisions based on feelings without the need for indepth analysis and evaluation. This decision-making style will certainly affect the resolution of everyday problems encountered.

Figure 2A shows that decision making (DM) for male is identified as having the ability in the very high to very low categories, while DM for female is classified as very high to low, so both are in the Medium category (Male: $39.69 \%$, and Female: $50.79 \%$ ). As many as $61.29 \%$ of male have a style with a medium to very low category and $31.71 \%$ in a high to very high category. The same results were shown by female students where $76.18 \%$ were in the medium to low style category and $23.82 \%$ for the high to very high categories. Based on these results, male's decision-making abilities are higher than female's. However, they are generally in the low category.

Figure 2B shows that students in semester II-VI generally have a decision-making style in the medium category and it is higher than other categories $(34.34 \%-44.27 \%)$, while students in semester VIII have a decision-making style in the high category (44.44\%) compared to other categories. However, the number of students in semester II who have a decision-making style high-very high $(36.36 \%)$, medium-very low (63.64\%), who have the ability of the high-very high category in the third semester is $31.58 \%$, and medium-very low at $68.42 \%$. In the fourth semester it is in the category high-very high $(28.89 \%)$, mediumvery low $(71.11 \%)$. Students in semester VI have the ability to make decisions in the high-very high category of $27.48 \%$, and medium-very low as much as $72.52 \%$. Furthermore, for semester VIII, the decision-making style for the category of high-very high is $50 \%$ and medium-very low is $50 \%$. This data shows that the students' decision-making style based on class (semester II-VI) is still in the medium to very low category, while semester VIII students have the same abilities between the medium-very low and high-very high categories.

The results based on region as in Figure $2 \mathrm{C}$ shows that the number of students from the western region who have a style of taking in the high to very high category is $33.12 \%$, the medium to very low category is $66.88 \%$. For students who come from the eastern region, the students' decision-making styles in the high-very high category is $26.89 \%$, the medium to very low category is $73.11 \%$. Students who come from western regions have a higher decision-making style. Even so, in general both styles are still dominated by the medium to very low category.

The ability of decision-making styles based on the universities as in Figure 2D shows that the number of students from state universities has slightly lower abilities in the high to very high category (29.79\%), compared to students from private universities $(31.87 \%)$. However, in general the percentage of decision-making style abilities in the two groups of universities is still in the medium to very Low category (70.21\% for public universities and $68.13 \%$ for private universities). 

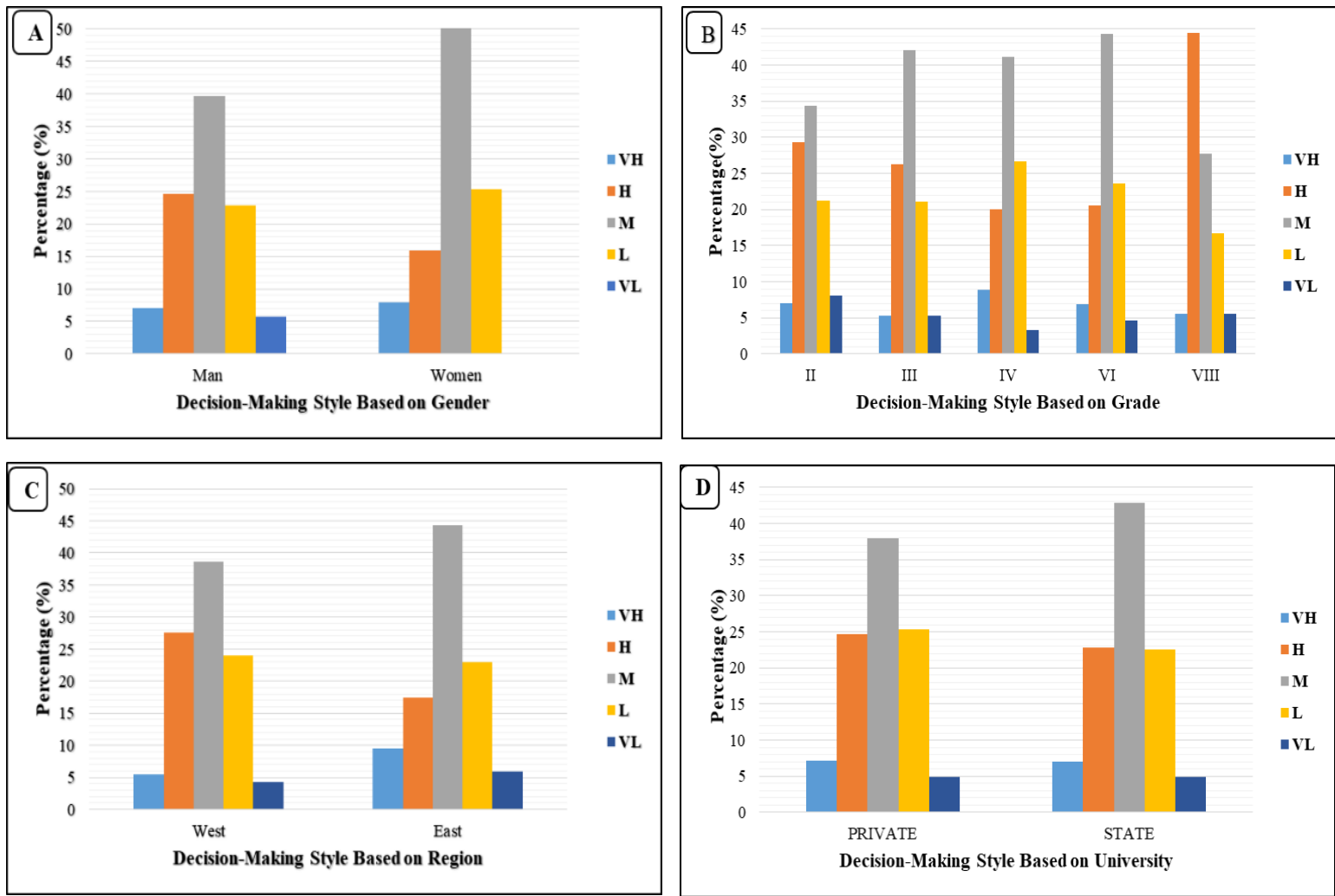

Figure 2. Graphic decision-making style based on gender, grade, region, university

Decision making directly linked to students' cognitive ability. In the process to make decision, students will analyze to have informed decision. Decision-making involves cognitive process; This regulatory process is related to a person's ability to make decisions so that choices become better [27]. In addition, Lundstrom, et al. [28] supported by Eastwood, et al. [29] also states that the main basis for decision-making is understanding the concept. Thus, students who have low decision making skill tend to affect their cognitive abilities and the concept understanding [30]-[33]. Someone who makes a decision will understand the decision framework in order to present it again. Thus, the decision maker will define how the decision is made by considering the norms, values and habits of the decision maker. That is, the decision maker can involve certain values and norms in accordance with the problems presented and contextualized.

Cases that are still considered new in school and courses programs include the relationship between science and society. The problem is some administrators and teachers in education do not yet know that this is very important to implement. Every teaching that is carried out is only based on content, resulting in students being unable to apply thinking skills and knowledge outside their school environment in the science context. In addition, students become passive in working in teams and are less skilled in solving problems in the form of decisions. It is known that a successful learning environment, these skills are generally very important. Sometimes teachers experience failure in directing and guiding students to solve problems through decision making. In addition, many teachers do not consider it important to motivate students' moral decision making. Many students are known to have less potential in making decisions especially about socio-scientific matters. The decision-making process in scientific cases has not been widely applied so far.

Implementation of an approach, method or strategy that potential to improve students' decision making with the multicultural characteristic in Indonesia, gender, grade, region as well as university context are crucial to conduct. Decision making skill can be enhanced through the integration of socio-scientific issues (SSI) in the biology classes [34]-[39]. SSI involves social and scientific issues that are controversial in society. SSI is feasible to be applied in Indonesia because it is faced with the complexity of various cultures and traditions. This is known as an approach so that teachers can be more creative in making the science learning process better and relevant to students' lives. Moral problems related to decision making can be done with student exposure. The benefits are that students become more scientifically literate and individually developed, develop decision-making abilities, and are more active in participating. The controversial of 
socio-scientific issues in science lessons will potential to train students who are objective in their decisionmaking processes. As previously known, cases about the relationship between science and society are rarely applied, so they are new things in schools. Teachers only teach based on content so that students have poor knowledge of science and are not skilled [40]. In addition, teachers have not developed much student potential in the context of decision making [41]. This means that decision making in this case is very important to be applied in science.

Studies have revealed that SSI potential to challenge students' rational, social, and emotional skills [42]-[44]. Additionally, SSI can serve as a useful context for learning specific science content knowledge, understanding of the nature of science and addressing citizenship education [45]-[50]. Moreover, having students collaboratively work on SSI can help them learn better through cognitive interaction and knowledge co-construction among learner of diverse background and prior knowledge. However, work with SSI puts new demands on teachers in that they must organize the classroom work differently by introducing valueladen arguments and discussions which might be unusual for some science teachers.

\section{CONCLUSION}

This study found that in general the decision-making style related to socio-scientific issues (SSI) of pre-service biology teachers mostly has low analytic decision style. However, in this case, the factors of gender, grade, region, and university should be considered in designing a suitable learning model to improve students' decision-making skills through SSI integration.

\section{ACKNOWLEDGEMENTS}

This research was supported by the Ministry of Finance and Research and Technology of Higher Education through the BUDI DN scholarship program.

\section{REFERENCES}

[1] M. U. Genisa and B. Subali, "Socio-Scientific Issues Implementation as Science Learning Material," International Journal of Evaluation and Research in Education, vol. 9, no. 2, pp. 311-317, 2020.

[2] P. Vincent-Ruz and C. D. Schunn, "The nature of science identity and its role as the driver of student choices," International Journal of STEM Education, vol. 5, no. 1, p. 48, 2018.

[3] D. L. Zeidler, B. C. Herman, and T. D. Sadler, "New directions in socioscientific issues research," Disciplinary and Interdisciplinary Science Education Research, vol. 1, no. 1, pp. 1-9, 2019.

[4] S. C. Fang, Y. S. Hsu, and S. S. Lin, "Conceptualizing socioscientific decision making from a review of research in science education," International Journal of Science and Mathematics Education, vol. 17, no. 3, pp. 427-448, 2019.

[5] Ü. Demiral, and H. Türkmenoğlu, "The relationship of preservice science teachers' decision making strategies and content knowledge in socio-scientific issues," Uludağ Üniversitesi Eğitim Fakültesi Dergisi, vol. 31, no. 1, pp. 309-340, 2018.

[6] F. Lieder, T. L. Griffiths, and M. Hsu, "Overrepresentation of extreme events in decision making reflects rational use of cognitive resources," Psychological Review, vol. 125, no. 1, pp. 1-32, 2018.

[7] K. Hamilton, S. I. Shih, and S. Mohammed, "The development and validation of the rational and intuitive decision styles scale," Journal of Personality Assessment, vol. 98, no. 5, pp. 523-535, 2016.

[8] P. A. Klaczynski and J. M. Cottrell, "A dual-process approach to cognitive development: The case of children's understanding of sunk cost decisions," Thinking \& Reasoning, vol. 10, no. 2, pp. 147-174, 2004.

[9] E. S. Lund, I. Bråten, C. Brandmo, E. W. Brante, and H. I. Strømsø, "Direct and indirect effects of textual and individual factors on source-content integration when reading about a socio-scientific issue," Reading and Writing, vol. 32, no. 2, pp. 335-356, 2019.

[10] M. T. Hora, J. Bouwma-Gearhart, and H. J. Park, "Data driven decision-making in the era of accountability: Fostering faculty data cultures for learning," The Review of Higher Education, vol. 40, no. 3, pp. 391-426, 2017.

[11] Y. Cosku, "A comparative study on university students' rational and experiential thinking styles in terms of faculty, class level and gender variables," Universal Journal of Educational Research, vol. 6, no. 9, pp. 1863-1868, 2018.

[12] G. Calabretta, G. Gemser, and N. M. Wijnberg, "The interplay between intuition and rationality in strategic decision making: A paradox perspective," Organization Studies, vol. 38, no.3-4, pp. 365-401, 2017.

[13] M. Sakschewski, S. Eggert, S. Schneider, and S. Bögeholz, "Students' Socioscientific Reasoning and Decisionmaking on Energy-related Issues-Development of a measurement instrument," International Journal of Science Education, vol. 36, no. 14, pp. 2291-2313, 2014.

[14] H. Gresch, M. Hasselhorn, and S. Bögeholz, "Training in decision-making strategies: An approach to enhance students' competence to deal with socio-scientific issues," International Journal of Science Education, vol. 35, no. 15 , pp. 2587-2607, 2013.

[15] A. Rachmatullah and M. Ha, "Examining high-school students' overconfidence bias in biology exam: a focus on the effects of country and gender," International Journal of Science Education, vol. 41, no. 5, pp. 652-673, 2019. 
[16] H. S. Chang and H. J. Lee, "College students' decision-making tendencies in the context of socioscientific issues (SSI)," Journal of the Korean Association for Science Education, vol. 30, no. 7, pp. 887-900, 2010.

[17] H. P. Rizal, P. Siahaan, and G. Yuliani, "Implementation of socio-scientific issues instruction to fostering students' decision making based gender on environmental pollution," Journal of Physics: Conference Series, Vol. 812, No. 012012, pp. 1-6, 2017.

[18] H. P. Rizal, G. Yuliani, and P. Siahaan, "The relationship of science knowledge and decision-making based on gender on socioscientific issues," 1st International Conference on Advanced Multidisciplinary Research (ICAMR 2018). Atlantis Press, 2019.

[19] A. Almukhambetova and A. Kuzhabekova, "Factors affecting the decision of female students to enrol in undergraduate science, technology, engineering and mathematics majors in Kazakhstan," International Journal of Science Education, vol. 42, no. 6, pp. 934-954, 2020.

[20] K. J. Saunders and L. J. Rennie, "A pedagogical model for ethical inquiry into socioscientific issues in science," Research in Science Education, vol. 43, no. 1, pp. 253-274, 2013.

[21] S. Y. Liu, C. S. Lin, and C. C. Tsai, "College students' scientific epistemological views and thinking patterns in socioscientific decision making,” Science Education, vol. 95, no. 3, pp. 497-517, 2011.

[22] K. Piatek-Jimenez, J. Cribbs, and N. Gill, "College students' perceptions of gender stereotypes: making connections to the underrepresentation of women in STEM fields," International Journal of Science Education, vol. 40, no. 12, pp. 1432-1454, 2018.

[23] Y. C. Lee, M. Grace, W. Rietdijk, and Y. C. Lui, "A cross-cultural, cross-age, and cross-gender study of Hong Kong and UK secondary students' decision making about a biological conservation issue," International Journal of Science Education, vol. 41, no. 18, pp. 2696-2715, 2019.

[24] C. Ottander and M. Ekborg, "Students' experience of working with socioscientific issues-a quantitative study in secondary school," Research in Science Education, vol. 42, no. 6, pp. 1147-1163, 2012.

[25] T. E. Nygren and R. J. White, "Assessing individual differences in decision making styles: Analytical vs. intuitive," Proceedings of the Human Factors and Ergonomics Society Annual Meeting, 2002, Vol. 46, No. 12, pp. 953-957.

[26] T. E. Nygren and R. J. White, "Relating decision making styles to predicting self efficacy and a generalized expectation of success and failure," Proceedings of the Human Factors and Ergonomics Society Annual Meeting, 2005, Vol. 49, No. 3, pp. 432-434.

[27] F., Böttcher and A. Meisert, "Effects of direct and indirect instruction on fostering decision-making competence in socioscientific issues," Research in Science Education, vol. 43, no. 2, pp. 479-506, 2013.

[28] M. Lundström, "Decision-making in health issues: Teenagers' use of science and other discourses," Doctoral Dissertation, Malmö University, 2011.

[29] J. L. Eastwood, T. D. Sadler, D. L. Zeidler, A. Lewis, L. Amiri, and S. Applebaum, "Contextualizing nature of science instruction in socioscientific issues," International Journal of Science Education, vol. 34, no. 15, pp. 2289-2315, 2012.

[30] H. Jho, H. G. Yoon, and M. Kim, "The relationship of science knowledge, attitude and decision making on socioscientific issues: The case study of students' debates on a nuclear power plant in Korea," Science \& Education, vol. 23, no. 5, pp. 1131-1151, 2014.

[31] N. G. Lederman, A. Antink, and S Bartos, "Nature of science, scientific inquiry, and socio-scientific issues arising from genetics: A pathway to developing a scientifically literate citizenry," Science \& Education, vol. 23, no. 2, pp. 285-302, 2014.

[32] T. D. Sadler and D. L. Zeidler, "The significance of content knowledge for informal reasoning regarding socioscientific issues: Applying genetics knowledge to genetic engineering issues," Science education, vol. 89, no. 1, pp. 71-93, 2005.

[33] T. D. Sadler, W. L. Romine, and M. S. Topçu, "Learning science content through socio-scientific issues-based instruction: A multi-level assessment study," International Journal of Science Education, vol. 38, no. 10, pp. 1622-1635, 2016.

[34] S. B. Gutierez, "Integrating Socio-Scientific Issues to Enhance the Bioethical Decision-Making Skills of High School Students," International Education Studies, vol. 8, no. 1, pp. 142-151, 2015.

[35] T. Tal and Y. Kedmi, "Teaching socioscientific issues: Classroom culture and students' performances," Cultural Studies of Science Education, vol. 1, no. 4, pp. 615-644, 2006.

[36] P. Reis and C. Galvão, "Teaching controversial socio-scientific issues in biology and geology classes: A case study," Electronic Journal of Science Education, vol. 13, no. 1, pp. 1-22, 2009.

[37] S. D. Kolst $\varnothing$, "Scientific literacy for citizenship: Tools for dealing with the science dimension of controversial socioscientific issues," Science education, vol. 85, no. 3, pp. 291-310, 2001.

[38] B. Lindahl, M. Rosberg, M. Ekborg, M. Ideland, C. Malmberg, A. Rehn, et al., "Socio-Scientific Issues--A Way to Improve Students' Interest and Learning?” US-China Education Review, pp. 342-347, 2011.

[39] K. A. Walker and D. L. Zeidler, "Promoting discourse about socioscientific issues through scaffolded inquiry," International Journal of Science Education, vol. 29, no. 11, pp. 1387-1410, 2007.

[40] M. Ratcliffe, "Pupil decision-making about socio-scientific issues within the science curriculum," International Journal of Science Education, vol. 19, no. 2, pp. 167-182, 1997.

[41] T. D. Sadler, F. W. Chambers, and D. L. Zeidler, "Student conceptualizations of the nature of science in response to a socioscientific issue," International Journal of Science Education, vol. 26, no. 4, pp. 387-409, 2004. 
[42] F. Lang, Y. Kammerer, K. Oschatz, K. Stürmer, and P. Gerjets, "The role of beliefs regarding the uncertainty of knowledge and mental effort as indicated by pupil dilation in evaluating scientific controversies," International Journal of Science Education, vol. 42, no. 3, pp. 350-371, 2020.

[43] J. W. Lin, T. S. Cheng, S. J. Wang, and C. T. Chung, "The effects of socioscientific issues web searches on grade 6 students' scientific epistemological beliefs: the role of information positions," International Journal of Science Education, vol. 42, no. 15, pp. 2534-2553, 2020.

[44] H. Cian, "The influence of context: comparing high school students' socioscientific reasoning by socioscientific topic," International Journal of Science Education, vol. 42, no. 9, pp. 1503-1521, 2020.

[45] T. D. Sadler, F. W. Chambers, and D. L. Zeidler, "Student conceptualizations of the nature of science in response to a socioscientific issue," International Journal of Science Education, vol. 26, no. 4, pp. 387-409, 2004.

[46] T. D. Sadler, S. A. Barab, and B. Scott, "What do students gain by engaging in socioscientific inquiry?" Research in Science Education, vol. 37, no. 4, pp. 371-391, 2007.

[47] J. M. Yahaya, A. Nurulazam, and M. Karpudewan, "College students' attitudes towards sexually themed science content: a socioscientific issues approach to resolution," International Journal of Science Education, vol. 38, no. 7, pp. 1174-1196, 2016.

[48] H. H. Wang, H. T. Chen, H. S. Lin, Y. N. Huang, and Z. R. Hong, "Longitudinal study of a cooperation-driven, socio-scientific issue intervention on promoting students' critical thinking and self-regulation in learning science," International Journal of Science Education, vol. 39, no. 15, pp. 2002-2026, 2017.

[49] S. R. Fowler and D. L. Zeidler, "Lack of evolution acceptance inhibits students' negotiation of biology-based socioscientific issues," Journal of Biological Education, vol. 50, no. 4, pp. 407-424, 2016.

[50] M. S. Topçu, J. A. Foulk, T. D. Sadler, S. Pitiporntapin, and N. Atabey, "The classroom observation protocol for socioscientific issue-based instruction: development and implementation of a new research tool," Research in Science \& Technological Education, vol. 36, no. 3, pp. 302-323, 2018. 